\title{
El romance familiar en la narrativa hispanoamericana decimonónica femenina: en búsqueda de modelos de ciudadanía
}

\author{
Claire Emilie Martín*
}

Resumen:

Mediante una abstracción de la relación nación-familia, la novela hispanoamericana del siglo XIX asimila las tensiones dramáticas heredadas de los modelos literarios franceses e ingleses, en los que los desvaríos amorosos y las pasiones se confrontaban con el desarrollo de las naciones modernas. En la obra de Clorinda Matto de Turner la familia se vuelve el núcleo a partir del cual el progreso social es posible; coloca a la mujer como eje rector de la familia y es su conducta la que condiciona el porvenir de la nación. A través de esta temática las jóvenes repúblicas intentan lograr la transformación social que estimuló las independencias. En este artículo se expone dicha problemática a través de las teorías de Francine Masiello y D oris Sommer, tomando en cuenta la metáfora del "romance familiar o nacional", que sirve como base teórica para el análisis de esta etapa de formación literaria hispanoamericana, y de la simbología que Matto de Turner utiliza para ilustrar su versión del funcionamiento social.

Palabras clave:

Novelas nacionales decimonónicas, narrativa decimonónica, narrativa escrita por mujeres, novela hispanoamericana del XIX, narrativa femenina, Clorinda Matto de Turner.

${ }^{*}$ California State University. 
Las novelas de Clorinda Matto de Turner A ves sin nido (1889), Índole (1891) y H erencia (1895) se espejean en un intento de ficcionalizar los vicios y corrupciones de la sociedad peruana para apuntar de manera aparentemente unívoca hacia un ideal republicano ilustrado. Estas novelas utilizan la unidad primaria constituida por la familia y llevan en círculos concéntricos a la esfera pública los oscuros vicios de sus personajes. Las teorías expuestas por Francine Masiello y D oris Sommer, entre otros críticos, sobre la útil metáfora del "romance familiar o nacional" como andamiaje teórico, proveen una base sólida desde la cual podemos iniciar el análisis de la novelística decimonónica.

Clorinda Matto proyecta en su obra una conciencia aguzada del papel que le asigna su educación y su proximidad a las esferas de poder. Como muchas de las escritoras de su época, hay en ella un celo republicano de visos románticos y tendencias realistas-naturalistas que la incitan a verter en la página los males de que adolece la nación peruana y los paliativos y curas a su disposición. Los "romances nacionales" se adhieren al discurso político y cultural de las nuevas naciones y diseminan las nuevas ideas emanadas de la ilustración europea filtrada ya por el tamiz de las realidades nacionales latinoamericanas. ${ }^{1}$

Si bien A ves sin nido ha recibido sostenida atención crítica, las restantes novelas mencionadas han sido poco estudiadas hasta muy recientemente. No obstante, debemos leerlas como un plan, una agenda revolucionaria por parte de esta escritora que pagó con creces su audacia. El clero, el gobierno, la maledicencia de una clase pudiente alejada del drama diario de las poblaciones desposeídas, reciben la crítica mordaz y valiente de esta intelectual activista que supo vivir sus convicciones.

En este estudio propongo una exploración de la simbología utilizada por Matto de Turner para ilustrar la visión maniquea de su

${ }^{1}$ Este importante concepto ha sido estudiado en profundidad por D oris Sommer, Francine Masiello, Elizabeth Garrels, John Brushwood, Adriana Méndez Ródenas, entre muchos otros críticos. 
teoría sobre la herencia en la novela homónima. La compleja feminización de la sociedad, la porosidad del espacio doméstico y del público, la carga simbólica del vestuario y los adornos, el lenguaje secreto del juego de miradas, y el concepto del "otro" como espejo de vicios y virtudes constituyen la red de signos que dificultan una lectura transparente.

En $\mathrm{H}$ erencia, los personajes se separan nítidamente en dos polos opuestos: Margarita/ Ernesto y Lucía/ Fernando quienes representan los nuevos valores republicanos ilustrados, y por otro, Camila/ Aquilino, Nieves/ Aguilera, Inés de Robles, y Espíritu Cadenas, quienes representan el estancamiento de una sociedad materialista e hipócrita. Si nos atenemos exclusivamente a la teoría naturalista del determinismo biológico y ambiental expuesta abiertamente a través del texto, las categorías parecen acomodarse fácilmente a cada personaje. Sin embargo, hay grietas en el aparato teórico que sirve de andamiaje a las ideas de la autora. El análisis de la caracterización de los personajes y su circunstancia y los elementos simbólicos que abundan en la narrativa indican una ruptura entre los ideales románticos basados en un catolicismo temperado, aunque sólidamente arraigado en la experiencia de la autora, y la visión pseudocientificista y materialista que propone a lo largo de la novela. De esta tensión surge una ambivalencia no resuelta a pesar de la aparente nitidez en que se desarrollan las ideas motrices.

Notamos esta ambivalencia en la caracterización psicológica de los personajes, y en especial de Margarita, en los ámbitos que determinan el comportamiento y esconden las dobles vidas, en las descripciones románticas cargadas de erotismo, y en la visión dual de Lima. El proceso de feminización romántica de la sociedad en las emergentes repúblicas genera una dinámica compleja y ambigua en la cual el concepto de mujer dentro de la imaginación política masculina representaba los valores y virtudes de la nación. Pronto, estas imágenes de virtud femenina comenzaron a competir con visiones de la mujer como caos y desorden (Masiello 19-20).

El matrimonio está en la base del orden social de la nueva sociedad republicana. Las alianzas extramaritales constituyen una seria 
amenaza a la estructura familiar y por ende nacional, no ya en términos de moralidad sino en términos de valores cívicos. Como lo ha señalado Francine Masiello, los miembros liberales de la intelectualidad, devotos de los programas de la unidad nacional y el progreso, utilizaron el ejemplo de la mujer para construir argumentos de libertad. Hicieron un llamado para terminar con los matrimonios concertados, predominantes en los tiempos de Rosas, equiparando el contrato entre los padres con la prostitución legalizada de sus hijas. D oris Sommer establece una "política erótica" por la cual en el espacio del romance nacional los conflictos de la nación se resuelven en la imagen del amor heterosexual. Los antagonismos políticos, de clase, raciales, y culturales se allanan mediante el interés común en llegar a la felicidad y no ya a través de la coerción. La conquista amorosa como metáfora de la situación en estas naciones emergentes es sumamente apropiada pues el pueblo debía ser cautivado, enamorado paulatinamente para cumplir los deseos de una clase dirigente en pos de una nación ideal.

En H erencia, la conquista amorosa es de doble signo: lleva a la perdición 0 al amor puro y republicano. La caza la dan tanto mujeres como hombres. Nieves, Inés y Camila, de forma diversa, rompen con las convenciones para satisfacer sus deseos eróticos. La carencia de valores ciudadanos determina las elecciones de pareja de las jóvenes casamenteras resultando en alianzas truncadas, en ideales desplazados. La dinámica romántica se convierte así en una economía de mercado y los diferentes ámbitos urbanos: la ciudad, los salones, las casas, las calles y los lugares públicos frecuentados por las diferentes clases, se vuelven el locus de las transacciones carnales y de conveniencia.

El matrimonio de D oña Nieves y José Aguilera ejemplifica la dinámica malsana en que se basa su relación. Se casan por "asalto de honor". Él deja su puesto de Sargento Mayor pues la dote de Nieves le permite jubilarse; él pierde su libertad puesto que ella es la fuerza dominante en la relación. D on José Aguilera anuncia a quien quiera oírlo: "casarse es suicidarse" (39). Poco auspiciosa es esta pareja como fundamento de la nueva república. Otros perso- 
najes se suceden para iluminar el fracaso del matrimonio en esta sociedad. Inés de Robles, la amiga de Nieves que anuncia su intención de seducir a Fernando, el marido de Lucía; Camila, la hija de Nieves que sucumbe ante la seducción de Aquilino, el comenciante italiano, y Espíritu, la mulata engañada, madre de dos hijas (como D oña Nieves). La narradora expone una interesante teoría sobre la causa de la abundancia de hijas:

La principal causa que la medicina reconoce para la mayor propagación de las mujeres está en el exceso de los padres que abusan del placer sin medida; y por eso, allá donde la moderación rige al amor, nacen varones robustos, moral y físicamente. (54)

La mujer es entonces producto de los instintos desmedidos de "la bestia humana" para utilizar el título de la novela de Émile Zola mencionado en $\mathrm{H}$ erencia y asociado con el bello Aquilino Merlo. Debemos mencionar de paso que el inmigrante italiano Aquilino Merlo trae consigo valores que amenazan el tenue equilibrio de las clases sociales limeñas. Su belleza, su aguda inteligencia, son puestas al servicio de los más bajos móviles. Su oscura herencia lo convierte en una amenaza real al orden social ya corrupto en su mayoría. Aquilino encuentra un terreno fértil donde propagar su mala herencia.

Inés de Robles se defiende de la reconvención de su amiga cuando le manifiesta su intención de hacer de D on Fernando Marín su amante, exclamando: “iY qué! ¿Estamos en los tiempos en que los hombres eran honrados? ellos, ¿qué ejemplo nos dan? ¿qué estímulo ofrecen para aquello que impávidos llaman virtud? ¿no tienen una querida a cada vuelta de esquina?" (60).

Los personajes masculinos de la novela han aprendido a discernir, a descodificar "la hembra destinada a funciones fisiológicas y la mujer que ha de ser la copartícipe de las espirituales fruiciones del alma" (33, las cursivas son mías). La dicotomía hembra/ mujer queda claramente asentada al inicio de la novela desde la perspectiva 
de dos jóvenes casanovas, al acecho de la nueva presa que constituyen las hermosas serranas Lucía y Margarita. Enrique de la Guardia y Carlos Pimentel aguzan el oído y la vista, siguen de cerca estas mujeres como buenos catadores de nuevas delicias "en el mercado del amor" (35). La cacería de la conquista y el afán de aparentar llevan al despilfarro en busca de una elusiva perfección femenina localizada al alcance de todas aquellas de cierta posición social para adquirir: "la serie de sorpresas que narcotizaba a las mujeres, las engañaba como a tiernas criaturas, y haciéndolas perder todo juicio, las obligaba a dejar el presupuesto de la casa, resignándose con verdadero heroísmo al ayuno del estómago" (38). Anne K. Mellor, hablando de la obra de Mary Wollstonecraft, $\mathrm{V}$ indication of the Rights of $\mathrm{W}$ omen, nota que entre las grandes locuras femeninas, según Wollstonecraft, se encuentra la obsesión con la moda y las apariencias, resultado de la reificación estética de la mujer perpetrada por el sexo opuesto (Mellor 37).

La división entre el dominio de lo público y de lo privado (el hogar) es otra dicotomía que parecería no admitir la permeabilidad de ambas esferas. Para la mujer del siglo diecinueve el hogar se convirtió en el sitio desde donde entablar un diálogo con la sociedad. Francine Masiello nota que desde allí se definió la función de la educación, se debatió el futuro de la nación, se organizó la lucha contra la tiranía, se preparó la agenda protofeminista, se debatió la lengua oficial y se profesionalizó la escritura de la mujer intelectual (11-12).

El locus de las transacciones humanas está en la ciudad-capital: "Lima, la engreída sultana de Sud-América celebraba ese festín cuotidiano del crepúsculo [sic]" (30). Se expresa en esta imagen una feminización y exotización del medio urbano debido no sólo al rico pasado colonial de la ciudad sino a factores como la inmigración extranjera y el heterogéneo elemento humano local. Las callejuelas, las pulperías, los almacenes de ropa, los salones, las plazas, las iglesias, todos ellos se convierten en parte de un organismo vivo, pulsante, por donde pasan los personajes en busca de su felicidad y hacia su perdición. Ningún espacio permanece neutro. Los perso- 
najes llenan el signo del espacio que ocupan con su valores o bien decadentes o bien virtuosos. Por ello, en el salón de baile de los Aguilera se trama la infidelidad, el matrimonio por conveniencia, la seducción de Camila, la envidia y la maledicencia y, por otra parte, emerge el amor puro entre Ernesto Casa-Alta y Margarita bajo la discreta aunque alerta mirada de los esposos Marín.

D oña Nieves Aguilera desfigura el espacio doméstico al hacerlo escenario de las transacciones carnales y la batalla por la apariencia. El hogar, ambiente determinante para la educación de los hijos, se transforma en el mencado público, extensión de la ciudad vista en términos de un loaus donde pululan los seres en un constante "hormigueo humano" que abarca desde la taberna aristocrática hasta el salón y los almacenes de inmigrantes.

La porosidad del espacio doméstico se expresa en la fácil conversión del ámbito hogareño en espacio público atado a reglas y convenciones laxas y perniciosas como hemos mencionado anteriormente. Las fiestas y reuniones "en que a la par se quiebran las copas de vino y la honra de las damas" (41) atraen por su fulgor y su promesa de felicidad, al tiempo que esconden el vicio, la corrupción y el mal. El señor Aguilera recrimina a su mujer su vanidad y su orgullo como pésimo ejemplo para las dos hijas: "Mira, Nieves, que a tus hijas no las estás educando para madres de familia y madres de ciudadanos: mira que el oropel envenena el corazón" (41). A lo cual responde Nieves: "Aquí nadie endereza lo que yo hago con mi dinero, con mis hijas, en mi casa" (41). Nieves ejerce su poder dentro del ámbito de lo doméstico y su fortuna respalda su autoridad.

Mientras tanto, la figura masculina ha quedado emasculada y más tarde este marido repudiado, en conversación con su amigo Pereira, concuerda con aquél quien: "aseguraba de buena fe que en el país estaban perdidos y corrompidos los hombres y que quizás le iría mejor a la patria echándose en brazos de las mujeres. D oña Chepa Arias, mi amigo, es un genio, verdaderamente un genio. Yo le daría sin reparo la cartera de guerra. Para Hacienda, Pepe, tienes ahí a tu mujer" (42). La corrupción de los miembros del congreso 
vuelve a hacer su aparición estrechamente vinculada a la mujer: "¿Q ué hacen aquí todos esos diputados de provincia que viene cada año más raros? Se imaginan que los pueblos los han mandado a enamorar a su costa, y son las mujeres su preocupación, y las mujeres su labor parlamentaria, y las mujeres las que consumen las dietas" (65). En estos comentarios y en otros se refleja el problemático cambio en la división de los géneros y sus papeles dentro de una sociedad paralizada por sus propios prejuicios de clase, de género y raciales.

La casa de los Aguilera después de la fiesta se contrasta radicalmente con la de los esposos Marín: "En los salones de los Aguilera las flores estaban marchitas, los semblantes ajados; trocado el color de las sedas engañosamente presentado por la luz del gas y de las bujías; estaban manchados y estrujados los guantes... las voces resfriadas, la atmósfera saturada de ese vaho que despiden los residuos de una fiesta; así como la descomposición del cadáver de una mujer hermosa" (86). Esta visión empañada por el vicio dentro del ambiente del hogar se halla diametralmente opuesta a los ideales de la familia republicana expuestos en las narrativas decimonónicas románticas y realistas.

Francine Masiello en su estudio sobre la ficción decimonónica argentina antes mencionado, establece que los autores escribieron narrativas de asunto doméstico y destinos románticos para explicar la historia y predecir el porvenir de la nación. D oris Sommer argumenta que los modelos literarios franceses e ingleses debían ser corregidos y mejorados. Las relaciones extramaritales y los devaneos amorosos de las novelas europeas no se ajustaban al deseo urgente de construir la nación desde una base sólida. La novela hispanoamericana decimonónica destruye el triángulo amoroso europeo, lo endereza y lo simplifica. Las tensiones y conflictos están siempre en la periferia de los amantes (inocentes).

Si bien las novelas de Rousseau, Balzac y Richardson muestran las resquebrajaduras de la familia burguesa, las novelas americanas las evitan y las rellenan con la idealización de la nación-familia. La familia se transforma en una comunidad privada y pública a la vez 
y las alianzas de poder (político, educacional y económico) se fundan en las alianzas familiares (46-47). Clorinda Matto de Turner en su trilogía novelística pone en funcionamiento una crítica despiadada de la fragmentación de la familia cuando las mujeres se convierten en víctimas de sus propias pasiones y de los deseos carnales del clero para dejar de lado su papel de madres y esposas ilustradas. La religión, las instituciones políticas anquilosadas, la clase aristocrática decadente, se constituyen en factores determinantes en el destino de los personajes femeninos de Matto de Turner. Si la familia falla en su propio proyecto individual de felicidad doméstica, la nación se hará eco de ese fracaso. Pero las jóvenes repúblicas no pueden permitirse el lujo del fracaso, y por ende, la novela se convierte en eficaz utensilio de transformación social.

A partir de 1880 se opera un cambio en la representación cultural y literaria de la mujer, la familia y la nación como respuesta a las olas de inmigración, la investigación científica y el auge de la modernidad. La novela $\mathrm{H}$ erencia de Matto de Turner ilustra este afán de identificar el núcleo familiar como extensión de la nación y denunciar los males que la corroen desde dentro. Al mismo tiempo, es evidente la relación de ambivalencia entre los ideales republicanos ilustrados, el peso del pasado colonial aún operante, los modelos extranjeros y la fluidez de una sociedad que si bien se resiste al cambio, inevitablemente se inclina ante éste.

\section{Bibliografía}

Amstrong, Nancy. D esire and D omestic Ficion: A Political H istory of the N ovel. Nueva York: Oxford University Press, 1987.

Cornejo Polar, Antonio. Clorinda Matto de Turner, novelista. E studios sobre Aves sin nido, Índole y Herencia. Lima: Lluvia Editores, 1992.

D enegri, Francesca. El abanioo y la cigarrera. L a primera generación de mujeres ilustradas en el Perú. Lima: Flora Tristán, 1996. 
Hunt, Lynn. The Family Romanoe of the French Revolution. Berkeley: University of California Press, 1991.

Kerber, Linda $\mathrm{K}$. W omen of the Republic. Intellect and Ideology in Revolutionary A meriœ. Nueva York: W. W. Norton \& Co., 1986. Masiello, Francine. Between Civilization and Barbarism. Women, $\mathrm{N}$ ation and Literary Culture in Modern A rgentina. Lincoln \& London: Nebraska University Press, 1992.

Matto de Turner, Clorinda. A ves sin nido. Lima: Peisa, 1973. , H erencia. Lima: Matto Hermanos, 1895. , Indole. Lima: Tipografía Bacigalupi, 1891.

Mellor, Anne K. Romanticism and G ender. Nueva York: Routledge, 1993.

Rodríguez-Luis, Julio. H ermenéutica y praxis del indigenismo. L a novela indigenista de Clorinda Matto a José María A rguedas México: Fondo de Cultura Económica, 1980.

Sommer, D oris. Foundational Fidtions. The $\mathrm{N}$ ational Romanoes of L atin A merica. Berkeley: University of California Press, 1991. 